\title{
Determinants of Teacher Effectiveness: Pedagogical and Didactic Training
}

\author{
Charalambos I. Konstantinou \\ University of Ioannina, Faculty of Education, GREECE \\ Ioannis Ch. Konstantinou \\ Educator, PhD, University of Ioannina, GREECE
}

Received: 29 December 2020 • Accepted: 4 April 2021 - Published Online: 21 April 2021

\begin{abstract}
The purpose of this article is to highlight the factors that decisively affect the effectiveness of the teacher in fulfilling his role, giving special importance to his pedagogical and didactic training. Initially, the role of the teacher is approached in relation to the mission of the school and the characteristics of an effective teacher. Subsequently, the content and the importance of pedagogical and didactic training for the exercise of the educational work are approached, as well as the additional reasons that impose it. In addition, the existing pedagogical and didactic training of current teachers is approached, in relation to the consequences of its absence for the educational process and the student. The article concludes with the final findings and remarks.
\end{abstract}

Keywords: school mission, role and effectiveness of the teacher, pedagogical and didactic training.

\section{Introduction}

The school, as a social and pedagogical institution with a defined structure, roles, arrangements and purposes, performs specific functions, through which, scientific, cultural and social qualities are promoted to students, such as knowledge, skills, values, rules, perceptions, behaviors and so on, as well as professional opportunities and positions. The teacher, who is responsible for carrying them out through the procedures of education, teaching, learning, evaluation, and socialization, plays, indisputably, a leading role in these functions, due to his position. These responsibilities, which the teacher has undertaken to carry out, constitute a complex and compound framework, in which interests, needs, demands and expectations arising from different sectors and carriers of social life are condensed.

The conscious or unconscious expectations of these social groups are complex, general, without differentiations and clarity, and, often, diametrically opposed or even contradictory. These expectations are manifested when the teacher fulfills his role and specifically through (Konstantinou \& Konstantinou, 2017; Liakopoulou, 2020):

- The organizational-administrative specifications of the school operation;

- The teaching of the curriculum as described in the school curricula and books;

(C) Authors. Terms and conditions of Creative Commons Attribution 4.0 International (CC BY 4.0) apply. Correspondence: Charalambos I. Konstantinou (Emeritus Professor), University of Ioannina, Faculty of Education, GREECE. E-mail: chkonsta@uoi.gr. 
- The attitude of parents and their representatives;

- The students' demand for understanding and satisfaction of their interests and needs;

- The criticism of public opinion, colleagues, representatives of the relevant sciences, etc.;

- The way the teacher addresses and manages these expectations.

The complexity and difficulty in implementing the role of the teacher are, in general, due to the fact that the teacher is authorized to carry out his responsibilities on the one side on the basis of the relevant administrative arrangements, such as laws, circulars, regulations, curricula, etc., and on the other in accordance with his scientific and pedagogical education and training and, overall, the formation of his personality.

As a result, the teacher is several times, in a confused state and under constant pressure, dominated by dilemmas and contradictions. The expectations of social groups, of course, do not appear in the same way in different periods. However, they are maintained and constantly increasing, depending on the political, cultural, economic, scientific, technological and, in general, social developments more generally, social progress, but also depending on the way the school itself is organized and operates in the social system. And, certainly, these expectations change, differ and vary in the individual levels of education, such as kindergarten, elementary, middle, and senior high school,

Pedagogical science has always been concerned with questions about the conditions and qualities that the teacher must possess to perform his complex and difficult role in an even and effective way. There are many different theoretical approaches around this topic, mainly in international and less in the Greek pedagogical, psychological and sociological bibliography. Many of the theories related to this issue are dominated by an ethical conception in describing the characteristics that compose the role and personality of the teacher.

In these theories the teacher is portrayed with ideals and qualities that are more specific to the role of the priest by modelling the behavior of Christ. There is also talk about "born educator", a "teacher's soul”, e.g., Spranger, Kerschensteiner, or an educational "pedo-trope" and "logo-trope", e.g., Caselmann, or for an educational "child counselor", e.g., Nohl, or for a teacher with a "pedagogical personality", e.g., Schneider, Döring, and "social mission" modeled on the pedagogical ideas and applications of Pestalozzi, such as pedagogical love. Other theories characterize as the main task of the teacher the "transfer of knowledge", e.g., Herbart etc. (Konstantinou, 2015; Reich \& Schiess 1984; Xochellis, 2015).

A basic observation that must be made in the ethical perceptions, which refer to the qualities of the teacher, is, whether it is possible to meet a teacher with the specific characteristics in the current school and social reality. And, of course, if one does not meet "such" teachers but "others", what is this or that that interferes and prevents their emergence and action? These signs refer almost self-evidently to the dominant problem of the Sciences of Education, which is the disharmony between theory and practice, as well as the connection between school and society.

This means that there is a question of parameters related to the nature, configuration and function of the role of the teacher. Namely, what are these factors, which are involved and, obviously, interact in the form that the role of the teacher takes in school reality, since the teacher is not just a set of qualities that constitute his personality, but much more is an individual, who performs a social role under certain space-time, working and personal conditions. 
2. School and teacher mission

At this point it should be pointed out that the role of the teacher is closely linked to the structure, operation and nature of the education system and, in particular, of the school as a social and pedagogical institution. After all, this is the reason that led to the perception that the teaching profession is a dependent and directed profession. For this reason, we start the approach of the subject from the school as a pedagogical and social institution, in which the teacher plays his role.

According to the relevant pedagogical and sociological theories (see more: Fend, 1981; Fingerle, 1987; Konstantinou, 1989; Konstantinou, 2015: 127-132; Xochellis, 2015), the mission of the school is summarized as follows (see Chart 1):

THE INDIVIDUAL ROLES OF THE TEACHER

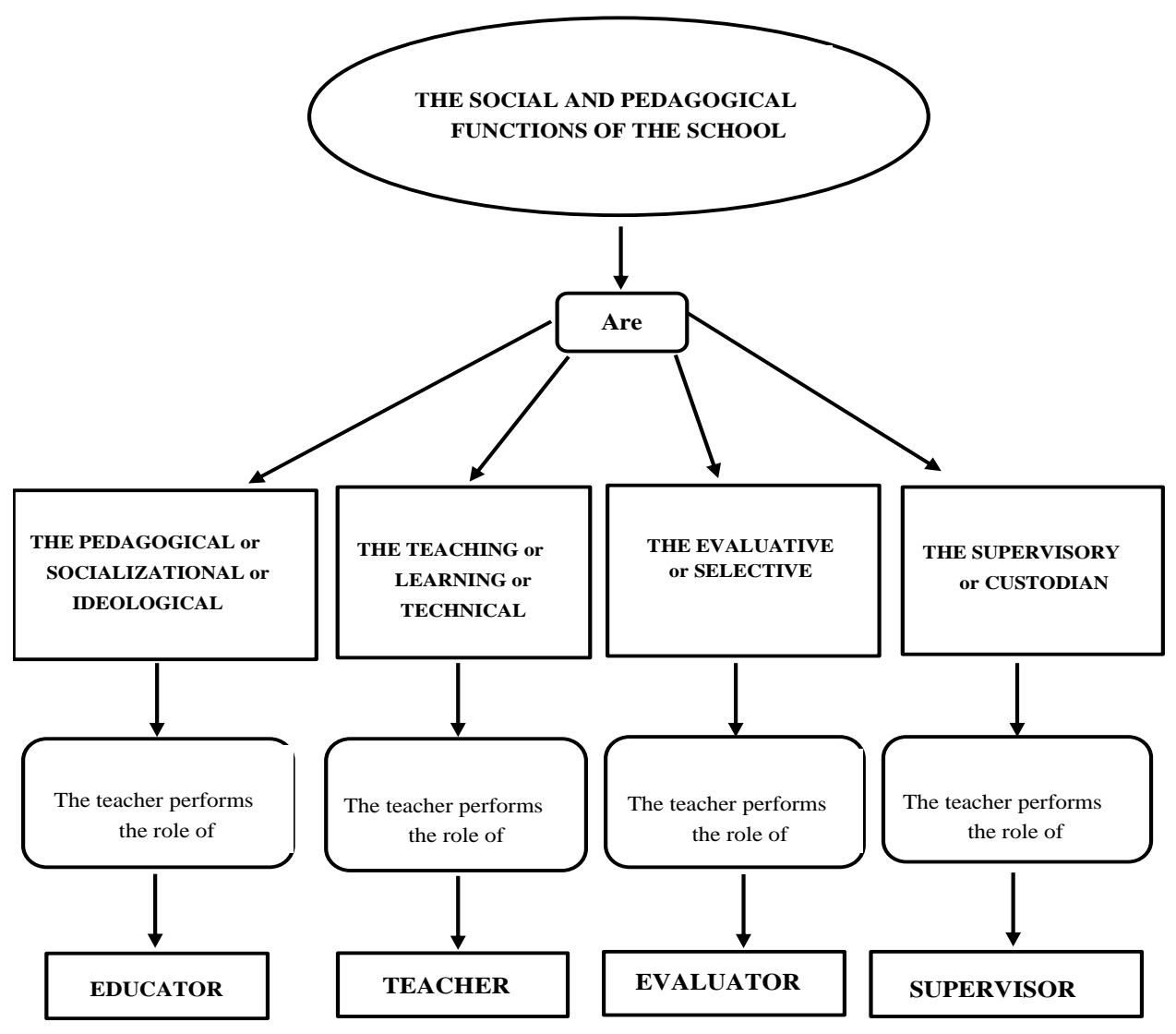

Chart 1. The individual roles of the teacher in relation to the school functions

Analytically it (Fend, 1981; Konstantinou, 1989; Konstantinou, 2015; Xochellis, 2015):

- The school educates and socializes the student, to shape his personality and contribute to his smooth integration into the social system. According to this function of the school, the teacher performs the role of the educator.

- The school teaches and learns, aiming to the development of student's cognitive, mental, and emotional levels. According to this function of the school, the teacher performs the role of the teacher.

- The school evaluates the student to determine whether he achieves the educational objectives and to identify any deficiencies and inadequacies, as well as the student's potential, aiming to receive feedback and improve the learning process 
and the integration of the student into the labor market. According to this function of the school, the teacher performs the role of the evaluator.

- Finally, the school supervises the student, releasing the parent from his pedagogical role, while his child is at school, and seeking to offer safe and decent living to the student. According to this function of the school, the teacher performs the role of the supervisor.

As found in this brief description and as we have highlighted in the introduction, the teacher, who is in charge of handling them through its procedures, undoubtedly plays a leading role in the school mission and, in particular, in its specific functions: education, teaching, learning, assessment and socialization.

In this way, the teacher seeks to create an educational environment where the child can develop his personality as smoothly and harmoniously as possible. His pedagogical efforts include the removal of factors that negatively affect the child's development. The school, that is, through education, seeks to "open the educational path to the student", according to the curricula and, overall, the orientations of the school.

This does not mean that the child should only acquire knowledge in specific subjects, for example history, mathematics, etc., but much more, the school aims to give pedagogical meaning to all its school processes, so as to contribute to an, as far as possible, complete development of the child's personality. To cultivate skills and familiarize him, namely, with the value system of society, contributing in such a way that the child becomes mature, autonomous, responsible, consistent, emancipated, free, democratic, with creative and critical thinking, with respect for the identity of others, with respect for culture and the environment, etc. (Giesecke, 1989; Hentig, v, 1988; Konstantinou, 2015).

In other words, and based on convergent pedagogical principles, a pedagogical relationship between the teacher and the child must be developed, which differs from other social relationships and which has the following characteristics (Brunner \& Huber, 1989; Konstantinou \& Konstantinou, 2017; Rutter, Maugham, Mortimer \& Ouston, 1980):

- Any effect should be aimed at the happiness of the child.

- The question referring to the child's happiness depends on historical and social factors.

- The pedagogical measures must be guided both by the present state of the child's development and its future potential for social life.

- Due to the pedagogical purpose, aimed at autonomous individual action and responsibility, any other foreign ("out-of-individual") effect must be inactivated.

- The social relationship between adult and underage individuals should not be coerced. This should be left more to the readiness and disposition of the educated person.

- The pedagogical relationship is a relationship of interaction, in which the individuals participating in it exert mutual influences and cause changes in themselves.

More specifically, many weighted or unbalanced factors are involved in the processes of education, teaching, learning, evaluation and socialization which affect them to a greater or lesser extent, even though the degree of their influence is not possible to be determined precisely. Experts in these fields can only approximately estimate the influence or involvement of these factors. In today's societies some environmental impacts are indeed almost irrepressible, and this concerns mostly the political and financial factors as well as the technological means, that is computers, the internet and so on. Therefore, the difference arises from the fact that the "others" 
who contribute to the child's education and socialization are neither definitely nor always oriented to the same factors, but to different rules, values and practices, for example to those of the employment market. Perhaps they are interested more in what is useful and profitable for the job market and not in what is good and acts in the interests of the child's development.

Could the child act in a competitive society based on the Christian-Greek values of the form of "love your neighbor as yourself", when he learns from an early age that in the exams promotional, introductory, etc. - the rule of competition, which is interpreted as "the end justifies the means", applies and, even more, when their place in higher education is determined by these exams? An effort, namely, that required the entire and comprehensive arousal of the whole family, the tuition centers, the educational system, etc. and, of course, the student's onerous, harrowing and often torturous devotion? Is it possible for someone to "filter" or classify and rationalize the pluralistic social interests and benefits, so that they act pedagogically and in the best interest normal development of the child? In other words, can the teacher combine all these so as to achieve a balance of the factors that influence the process of education, teaching, learning and socialization?

Consequently, the answer to the question concerning the kind of practices and messages that are cultivated and promoted through school reality and, especially, through the socializing function of the school, is: knowledge accumulation, competition, grade pursuit, individualism, servitude, formalism and the like. A reality that is, where the student cannot be considered as an individual with his own particularities, needs, interests and experiences. In other words, a reality that does not favor the harmonious and balanced physical and mental-emotional child development, since it is prevailed by situations of anxiety, fear, indifference and aggressiveness, that are anything but in line with the pedagogical goals. The question that arises in this issue is, which is the role of the teacher as a pedagogue in an institution characterized by bureaucratic structure and organization. Which are the teacher's qualifications, among others, in order to confront and cope with the child through pedagogical and teaching means, so that personal and social identity are developed as well as completeness in communication and practice.

\section{Qualities of an effective teacher}

By utilizing the information concerning all school functions and the teacher's role, one can illustrate, in a more distinct way, the educational, organizational, practical and personal features that a teacher should have in order to join the category of "effective" teacher. First of all, what should be stressed at this point is that the form of practices, which are used by the teacher during the pedagogical communication with his students, depends on the role played by the teacher himself in school reality as the key factor of all the school processes. More precisely, the practices that are used while a role is fulfilled depend on the existing occasion, the kind of influence exerted on that role and the status that the person has in this specific occasion. Methodologically, it has been understood that in order to interpret and evaluate a specific behavior and then classify it, one must subsume it in a semantic context (occasion), which is determined by time, place, organization and the cultural standards of a society. That is, whichever meaning is given to a specific action, comprises an interdependence between the rule that regulates it and the semantic context to which it belongs. This point is particularly prominent since the role of the teacher depends to a decisive extent on the very hypostasis, structure, orientations and form of school operation as a social institution and, at the same time, on the political, economic, scientific, religious, technological and, generally, the socio-cultural conditions prevailing in its area of hypostasis.

First of all, from a general conceptual point of view, a teacher is considered effective when he effectively carries out his professional mission or else when he achieves the scientific and educational goals that are inextricably linked to his role. It has already been a pedagogical axiom 
that the way the teacher organizes and carries out the pedagogical communication plays a decisive role in the general attitude and behavior of the student towards the educational-learning process, but also towards the teacher himself (Doll, Zucker \& Brehm, 2009; Hentig, v. 1988; Kassotakis \& Flouris, 2005; Konstantinou, 2015: 142-144; Papandreou, 2002; Postic, 1995; Rutter, Maugham, Mortimer \& Ouston, 1980; Trilianos, 2004; Whitaker, 2013; Xochellis, 2015).

So, by that definition what plays an important role is (Ibid.):

- How the teacher educates and socializes his students;

- How he organizes the educational performance and how he implements the evaluation;

- If he takes the particularities of each student into account;

- If he takes the social reality into account;

- How he organizes the educational communication and relationship with the students;

- How he organizes and implements the discipline procedures;

- What kind of cooperation conditions he creates;

- How he deals with and handles behavioral issues, for example, indiscipline;

- Which is the way he engages students in the learning process;

- If he trusts and respects students and how he cooperates with them;

- Which is the way of using and administering justice;

- If he is ironic and insulative to students;

- If he encourages and rewards students;

- If he shows understanding and dedicates time to listening to students, and in general,

- How he treats his students, and so on.

In any case, and according to research data, effective, from a pedagogical, cultural and social point of view, is considered a teacher, who (Ibid.):

- Organizes appropriately, from a methodological point of view, the teaching and learning process;

- Evaluates the student based on the pedagogical content of the assessment by applying valid, reliable and objective methodological means;

- Takes the cultural and social reality into account, during the educational process and performance;

- Respects the needs, interests and, in general, the particularities of the student;

- Cultivates and strengthens teamwork and collaboration;

- Develops a relationship of trust with students;

- Strengthens his responsibility and autonomy;

- Jointly formulates rules that contribute to the delineation of student's behavior;

- Avoids stigmatizing and, generally, offending the student;

- Dedicates time to listen to students; 
- Is characterized by self-restraint, justice, equality, reliability, consistency, mildness and patience;

- Finally, he is the teacher who respects the student's personality and, above all, serves the learning, educational and, overall, pedagogical interests of the student, as well as the needs and promotion of society.

\section{Factors influencing the effectiveness of the teacher}

According to relevant research conclusions, a teacher is closer to the most effective fulfillment of his role (Karatzia-Stavlioti \& Lambropoulos, 2006; Konstantinou \& Konstantinou, 2017; Liakopoulou, 2020; OECD, 2011; Xochellis, 2015):

- When he has a comprehensive scientific, pedagogical and didactic training and reeducation;

- When he performs his work in a favorable context of school and working conditions;

- When his work is recognized from a moral, state, economic, social, and so on, point of view.

One of the most important features of the teacher's role is that it is determined by social expectations, which affect, in any case, the fulfillment of his role. This means that the way the teacher performs his role results from the function and interaction of a series of different factors. According to relevant research and theoretical models, the effectiveness in performing the role of the teacher is mainly influenced by the following three factors (Holzner, 1980; Konstantinou, 2015; Liakopoulou, 2020; OECD, 2011; Pyrgiotakis, 1992; Spanhel, 1981; Xochellis, 2015):

1) The scientific, pedagogical and didactic training and, in general, the professional formation and shaping of his personality that define to a great extent the interpretation he gives to his role.

2) The school reality with the organizational and operational conditions of the school, the role of the headteacher, the organization of school life, the school atmosphere and so on.

3) The wider social environment, meaning the various aspects of social life, such as culture/civilization, value system, politics, economy and so on. More specifically, he is undoubtedly influenced by social groups and their expectations which are attributed to his role by students, parents, colleagues, school management, public opinion, etc., and that manifest themselves not in the same form in different periods of time or differ from one group to another, or even between the members of the same group.

In the process of the following analysis, special emphasis will be given to the first factor that concerns the educational and professional composition of the teacher. Particularly, an attempt will be made to determine, mainly from a pedagogical point of view, the expectations that refer to: the role of the teacher and its individual qualities, the scientific and, in general, the professional composition that he has at his disposal for their implementation, in school reality where they are implemented and, finally in the factors of influence, which shape them and demand their realization. 
4.1 The importance of the pedagogical and didactic training as a factor of effectiveness for the teacher

By "pedagogical and didactic training-education" we mean the knowledge, abilities, skills and experiences acquired by the teacher during his education and training, and which are related to the educational system as a whole, and, especially, to school, as a daily workplace, and to the recipients of the educational processes, that is students themselves (Konstantinou, 2015: 145-146; Liakopoulou, 2020; Trilianos, 2004; UNESCO, 1999; Xochellis, 2015).

In other words, as pedagogical and didactic education-training we mean the qualifications a teacher should have from a pedagogical, didactic, sociological and psychological point of view, in order to perform his role as a professional teacher in a professional and effective way, that is as a pedagogue, teacher, evaluator and supervisor in the educational practice. The basis for this training is Pedagogy with its branches, Teaching Methodology, Psychology, Philosophy, Sociology of Education, Educational Evaluation and other disciplines both from the field of Social and Positive Sciences, which contribute and enrich this work with their research and theories (ibid.).

\subsection{Additional reasons that necessitate the comprehensive pedagogical and didactic training of the teacher}

The additional reasons, which necessitate the comprehensive and perfect pedagogical and didactic training of teachers, are the scientific, educational, cultural, economic, technological and political circumstances that have shaped a polyphonic, changeable and open to new context changes. This framework implies continuous rearrangements and developments in terms of information, knowledge, values, orientations and, in general, socio-cultural data. These specific adjustments and developments are so rapid that a teacher and a school reality, persisting in static, unilateral and outdated perceptions and practices, will increase immeasurably, catalytically and, perhaps, insurmountably the distance from socio-cultural prospects that determine their very existence.

Today, the need for a more complete professional training of teachers is urgently highlighted, in order to manage, in addition to the established pedagogical and didactic needs, the students' cultural diversity and the increased rates of their delinquency and deviant behavior. It should become clear that school is neither a place which provides a quantity of knowledge which is actually categorized into useful and non-useful, nor a place that considers the student as a storage receptor for their recruitment through unilateral and monotonous learning processes, nor is it a place where authoritarian practices and evaluative distortions are used. However, this means that the successful realization of the teacher's role must be considered in relation to changes concerning the orientations and the operation of the school itself, which has really diverged in this domain, as stated elsewhere.

\subsection{New roles for the teacher: "Social educator" and "social psychologist"}

For at least the last twenty years, there has been an increase in the rate of children disorders. This increase is estimated at 10-20\%, depending on the methodological approach to the issue. In particular, research data from many countries show that today's school children are lonelier and more oppressed, angrier and more unruly, more aggressive and more impulsive. School has now an important role upon this matter, developing and enhancing social skills in children, such as empathy, self-control, resolving dispute resolution, cooperation, collectivity, etc. (Doll, Zucker \& Brehm, 2009; Konstantinou, 2015; OECD, 2018). 
Searching for the reasons for the change in students' behavior, researchers find crucial changes in both the family environment and the wider social one, which are particularly noticeable in the Greek social reality, as a result, among others, of the economic and social crisis that has been plaguing the country for the past few years. This implies new data on student behavior, which must be handled by the teacher on a daily basis and for which he is not institutionally prepared and trained to deal with from a pedagogical and psychological point of view (Ibid.).

\subsection{The existing pedagogical and didactic training of today's teachers}

\subsubsection{Training of primary education teachers}

Regarding the students of the Departments of Primary Education in our country and according to their curriculum, this training is provided, since most of the total teaching hours refer to the pedagogical and didactic training of their students. Admittedly, a sufficient number of teachers, currently working in primary education, have graduated exclusively from Primary Education Departments in Greece and other Balkan countries, mainly of the former Yugoslavia, where the study was short-term, hardly in-depth, without the possibility of research and with particular emphasis on instructive formalism as well as "ready-made" and "complete" didactic models for imitation. These reasons were the main cause for the abolition of the Pedagogical Academies in Greece, which echoed the long-standing demand and struggle of the trade unions of both primary school and preschool teachers and, in particular, the Teachers' Federation of Greece (DOE). A demand, which was finally met with the establishment of the University Departments of Primary and Preschool Education (1983) (see also Pyrgiotakis, 1992).

\subsubsection{Training of secondary education teachers}

However, the situation in Greece is extremely problematic for secondary education teachers, given that the majority of students, having graduated from the respective university departments, have hardly had any pedagogical and instructive/didactic training, in both theoretical and practical form. Investigating the data in the study guides of the aforementioned departments reveals that the provided pedagogical and instructive/didactic training of the future high school educators is either insufficient or non-existent. In particular, the students of the departments of Biology, Mathematics, Informatics, Philology, Physics, Chemistry, etc., are given the opportunity, on an optional basis, to choose typically 1-2 Pedagogic Science and/or Teaching Methodology courses, taught in the departments of Primary Education or the departments of Philosophy, Pedagogy and Psychology; however, this is if they themselves wish to do so.

Insufficient to non-existent theoretical and practical pedagogical and instructive/didactic training led the Greek secondary school teachers to seek relevant knowledge through their own experiences, which is drawn either from their personal experiences as a student or from their experiences as a teacher from everyday practice. This means that the teachers have great confidence in the importance and exclusive validity of their experience, which is based on the data of an empirical way of acquiring knowledge. In other words, one can observe a "mythologizing" of empiricism based eminently on strict formalism, on a standardized teaching methodology, on subjectivity, amateurism, superficiality and arbitrary generalizations (Fragoudaki, 1993; Konstantinou, 2015; Papakonstantinou, 1986).

\subsection{Teacher training}

The problem, however, less in primary and more in secondary education, still exists at this time and is exacerbated by the fact that almost the majority of the teachers who serve at these 
levels, have little or no further pedagogical and instructive/didactic education at all. And, undoubtedly, the teacher's further education is not only imposed by their inadequate pedagogical and instructive training, but also by the social, cultural, scientific and technological needs and developments of our time; at a time when intense scientific developments and educational changes are being observed. This situation is exacerbated by the fact that most of the teachers go through almost their entire professional career, from appointment to retirement, without any professional renewal. At a time when many things are being abolished and others are being radically renewed, the professional renewal of teachers is becoming imperative. The activation and the contribution of the teachers to the modern social developments presupposes, but also imposes, better training, information on the use of new pedagogical and instructive/didactic methods and information as well as understanding of new educational goals (Konstantinou, 2015; Vergidis, 1993; Xochellis, 2015).

\subsection{The absence of pedagogical and instructive/didactic training and its impact on the educational process and on students}

Based on what was mentioned previously, it becomes clear that the pedagogical and instructive act, as a complex and multifaceted phenomenon, is a key element in the role of the teachers, who, in order to perform accordingly, need sufficient and thorough pedagogical and instructive/didactic knowledge, experience and skill. This means that, without a doubt, the absence of adequate pedagogical and instructive/didactic training has its effects on the quality of the processes of education, teaching, learning, socializing and evaluation and, in particular, on the quality of the pedagogical and instructive relationship of the teachers with their students. And this is happening, since a key point in the role of the teachers is the pedagogical interaction, through the mutual social relations and effects of which, important values, rules and messages are raised and promoted, which relate to the formation of the students' behavior and identity.

According to relevant research, the lack or the inadequacy of teachers' pedagogical and instructive/didactive training, in conjunction with other school and social factors, leads to empiricism and, consequently, to empirical and self-taught perceptions and practices. It also leads to pedagogical errors, pedagogical distortions, to pedagogical, instructive and evaluative practices of dubious value and, overall, to a degradation of the quality of the school's educational functions. In particular, it leads to (Konstantinou, 2015: 152-153; Konstantinou \& Konstantinou, 2017; Rutter, Maugham, Mortimer \& Ouston, 1980):

- distancing from the needs, interests and particularities of the student, on a cognitive, mental, emotional and social level;

- problematic situations concerning the pedagogical relationship between teacher and students, discipline, social behavior of the student, which appear more specifically in the form of the student questioning or even rejecting the teacher, the lesson or the school; in the form of lack of trust, respect, understanding, acceptance, but also with the use of insults, stigmatization and exclusion by the teacher.

- stereotypical and routine teaching-learning procedure, evaluation errors and, in general, educational and mainly teacher-oriented processes, which lead to the indifference and boredom of the student, and which cultivate sterile memorization, individualism, grading, competition and also do not promote critical thinking, self-motivation, cooperation, teamwork, interest and overall, the student's learning, mental, emotional and social activation. 


\section{Final findings and remarks}

From the approach of the subject, it is understood that the teachers are binding to the state in an administrative, professional, ethical and financial way, through a network of laws, rules, programs and regulations, which forces them to take into account, as per organizing the educational procedures, state standards and resolutions. This legal and regulatory framework that governs the teachers' relationship with the school forms a suffocating barrier that binds his action decisively and from which it is not easy to get rid of, without suffering the intended consequences. This context, although it changes from time to time depending on the goals and choices of the educational policy, at its core remains oppressive for teachers and is a point of conflict, leading them to dilemmas regarding their pedagogical autonomy. Thus, when the teachers in the classroom implement almost literally the specifications and objectives of the curricula, as well as the indicated methods outlined in the teacher's book, teacher autonomy seems to be out of the question, substituted by a kind of freedom within a binding framework.

The previous summary analysis also showed that education, teaching, learning, evaluation and socialization are part of the processes that decisively determine the teachers' professional activities, therefore, contribute to shaping their role. These processes are, at least in theory, established and institutionalized in school reality. In practice, however, one can observe an inadequate application of the standards associated with these processes, which, among other things, is inconsistent with the orientations of the Education Sciences. The insufficient processing of the pedagogical-didactive specifications is due both to the emergence of the school as a formal and non-processing organization with the predominance of the principles of power, hierarchy, bureaucracy, etc. as well as due to the professional identity formed by the teachers, through shortcomings, inadequacies and dysfunctions in their scientific and, mainly, in their pedagogical and instructive/didactive training. This development, however, constitutes the result of a broader function involving several factors related to political, economic, cultural and, as a whole, social reality. Consequently, addressing this situation at school should be combined, first and foremost, with a change in political and social choices and priorities.

It would, of course, be a methodological mistake to argue that all teachers treat the implementation of their role in the same way. There are clearly differences for everyone, due to many factors, personal, scientific, professional, ideological and so on. In addition, the teachers cannot be perceived as simple executive bodies of the educational authority, but as responsible and competent persons who organize the educational processes for the sake of the student and the social system. Where teachers were treated as executive bodies, they became passive receivers and executors of authoritarian orders, without their own free contribution to the procedures they had assumed to carry out.

In any case, it is difficult for the teachers to strike a balance between their own professional beliefs and aspirations (pedagogical dimension) and the social role they perform (socio-political dimension). Because formalism, hierarchy, bureaucracy and political choices and expediencies prevail in the relationship between the teachers and the school, nonetheless. For the successful confrontation of these two pressing parameters (pedagogical, socio-political) the teachers are required to possess quality attributes, related to the whole of their personality (Friderikou \& Folerou-Tserouli, 1991; Konstantinou, 2015; Pyrgiotakis, 1992).

Undoubtedly, however, the development that the pedagogical and didactic reality takes depends on the teachers' own presence, interpretation, participation, reaction and resistance. Because the way in which the teachers implement their pedagogical and official functions is a matter certainly related to their own personality. The fulfillment of their role would have the least conflicts and disputes, if the teachers organized the pedagogical and instructive processes based on the theories and findings of the Educational Sciences and the neighboring disciplines and interpreted the school and social reality with the needs, interests and 
particularities of each student always in mind. A function and a development which are, of course, not observed in today's school reality and, especially, in the realization of the role of the teacher. The lack of pedagogical and instructive/didactic training causes the teachers to develop feelings of insecurity, which, under the effect of influencing factors, lead them to a confused and uncertain situation, resulting to their "complying/conforming" more easily to the standards of educational ideology and power.

The teachers have a personal, autonomous and realistic professional identity, only when (Döring, 1980: 49; Konstantinou, 2015):

- they manage to combine theory with practice and when their educational activities are based on both of these levels;

- they define their role based on the institutionalized regulations, but they act while taking advantage of the opportunities for autonomous activity provided to them as well as making use of the advantages of their personal and professional identity. After all, any measures or objectives of the educational policy are implemented through the realization of the role of the teacher;

- the teachers, as subjects who act, they analyze and interpret autonomously and voluntarily the pedagogical situation in the classroom and the school and everything related to the realization of their role;

- they interpret the expectations or specifications of the influence groups and they delimit and manage their impact.

The teachers, based on the above pedagogical orientations, can change the form of the educational and organizational power that they have towards the students and, finally, they can treat them as persons with their own biography and their own peculiarities. However, a necessary condition for the implementation of such an educational role is the formation of a favorable school, professional and work environment by the educational policy pursued. Regardless of political expediencies, it is crucial that the state, through its educational policy, respects and stands by the work of teachers. After all, it is commonly accepted that teachers who are dissatisfied will perform less in the work they do. This means that the state must provide them with decent working conditions, which require, among other things, adequate resources for education, a safe and healthy school environment, scientific and professional autonomy, confidence in the teacher, high-quality initial education and continuing training and professional development.

And let us not miss the most comprehensive and important point, that society needs citizens with culture and education, as well as a school close to the actual/real life of the child. Close to social needs and social reality. And making use of a wise and genuine pedagogical saying by a great writer: "An ideal teacher is one who becomes a bridge for his student to cross over. And when he finally facilitates the crossing, he happily lets himself plunge, encouraging his student to build his own bridges.” N. Kazantzakis.

\section{Acknowledgements}

This research did not receive any specific grant from funding agencies in the public commercial, or not-for-profit sectors.

The authors declare no competing interests. 


\section{References}

Brunner, E., \& Huber, G. (1989). Interaktion und Erziehung. München: Union.

Döring, K. W. (1980). Lehrerverhalten: Forschung - Theorie - Praxis. Weinheim - Basel: Beltz.

Doll, B., Zucker, St., \& Brehm, K. (2009). School classes that promote mental resilience: How to create a favorable environment for learning, Chatzichristou, Ch. (scientific editing). Athens: Tipothito - Giorgos Dardanos. (in Greek).

Fend, H. (1981). Theorie der Schule. München-Wien - Baltimore: Urban und Schwarzenberg.

Fingerle, K. (1987). Von PARSONS bis FEND - strukturell - funktionalle Schultheorien. In: Tillmann, K.-J. (Hrsg): Schultheorien. Hamburg.

Fragoudaki, A. (1993). Insufficient education and lack of retraining of teachers: Main cause for the failure of the teaching operation. Sigchroni Ekpedefsi, t. 71, p. 26-30. (in Greek).

Friderikou, A., \& Folerou -Tserouli, F. (1991). The teacher at the primary school - A Sociological approach. Athens. Ypsilon.

Giesecke, H. (1989). Pädagogik und Beruf - Grundformen pädagogischen Handelns. Weinheim - München.

Hentig, v. H. (1988). Werte und Erziehung. In: Neue Sammlung 28, 3, S. 323-342.

Holzner, F. (1980). Der Lehrer in seinem Umfeld. In A. Schnitzer (Hrsg): Schwerpunkt Lehrerpersönlichkeit, S. 157-186. München.

Karatzia-Stavlioti, E., \& Lampropoulos, H. (2006). Evaluation, effectiveness and quality in education. In Educational Planning and Economy. Athens: Gutenberg. (in Greek).

Karras, K. (2011). The teacher in a changing world: A challenge for the today's pedagogy. Athens: Gutenberg. (in Greek).

Konstantinou, Ch. (1989). Entstehung, Leistungsfähigkeit und Perspektiven der griechischen Schulen am Beispiel Bielefelds. Frankfurt am Main: Haag + Herchen.

Konstantinou, Ch. (2015). The good school, the competent teacher and the suitable education as a pedagogical theory and practice. Athens: Gutenberg. (in Greek).

Konstantinou, Ch., \& Konstantinou, I. (2017). The evaluation in education: The evaluation of the educational work, the teacher and the student as theory and practice. Athens: Gutenberg. (in Greek).

Liakopoulou, M. (2020). Improving school effectiveness: From theory and research to practice. Athens: Gutenberg. (in Greek).

OECD (2011). Better Performances and Successful Reforms in Education: Recommendations for the Educational Policy in Greece. (in Greek).

OECD (2018). PISA 2018 results. (in Greek).

Papakonstantinou, P. (1986). From the pedagogical ideology to scientific pedagogy: The training content of the Greek teacher. In Th. Gotovos, G. Mavrogiorgos \& P. Papakonstantinou (Eds.), Critical pedagogy and educational practice (pp. 17-24). Athens: Sigchroni Ekpedefsi. (in Greek).

Postic, M. (1995). The educational relationship (trans. Touloupis, D. H.). Athens: Gutenberg.

Pyrgiotakis, I. (1992). The Odyssey of the teaching profession. Thessaloniki: Kyriakidis. (in Greek).

Reich, G., \& Schiess, G. (1984). Praxisbezogene Einführung in die Erziehungswissenschaft. Stuttgart - Berlin - Köln - Mainz. 
Ch. I. Konstantinou \& I. Ch. Konstantinou - Determinants of Teacher Effectiveness...

Rutter, M., Maugham, B., Mortimer, P., \& Ouston, J. (1980). Fünfzehntausend Stunden - Schulen und ihre Wirkung auf die Kinder. Weinheim - Basel: Beltz.

Spanhel, D. (1981). Die Rolle des Lehrers in unserer Gesellschaft. In W. Twellmann (Hrsg): Handbuch Schule und Unterricht, Band 1, S. 101-121. Düsseldorf.

Trilianos, A. (2004). Methodology of modern teaching, Book A ' \& B' . Athens: Aftoekdosi. (in Greek).

UNESCO (1999). Education. The treasure within. Report of the International Commission on Education in the $21^{\text {st }}$ Century chaired by J. Delors (trans. Center of Scientific Reasearch). Athens: Gutenberg. (in Greek).

Vergidis, D. (1993). Neoliberal educational policy and teacher training. Sigchroni Ekpedefsi, t. 69, p. 43-49. (in Greek).

Whitaker, T. (2013). A good teacher: What distinguishes him? Athens: Patakis. (in Greek).

Xochellis, P. (2015). Introduction to pedagogy. Fundamental problems of pedagogical science. Thessaloniki: Adelfi Kyriakidi. (in Greek). 